\title{
Determinants of Green Regeneration of Industrial Brownfield under Ecological Security Constraints: Model and Empirical Analysis Based on Grounded Theory
}

\author{
Yang Zhang ${ }^{1, *}$, Fangfang $Y e^{1, *}$ and Guangmin Zhang ${ }^{2}$ \\ 1 School of Management, Xi'an University of Architecture and Technology, Xi'an 710055, China \\ 2 School of Civil Engineering, Xi' an University of Architecture and Technology, Xi'an 710055, China; \\ zhanggm@xauat.edu.cn \\ * Correspondence: zhangyang@xauat.edu.cn (Y.Z.); yff@xauat.edu.cn (F.Y.); Tel.: +86-18192403900 (Y.Z.); \\ +86-15137196890 (F.Y.)
}

Citation: Zhang, Y.; Ye, F.; Zhang, G. Determinants of Green Regeneration of Industrial Brownfield under Ecological Security Constraints: Model and Empirical Analysis Based on Grounded Theory. Sustainability 2021, 13, 11396. https://doi.org/ $10.3390 /$ su132011396

Academic Editor: Adam Smoliński

Received: 16 August 2021

Accepted: 29 September 2021

Published: 15 October 2021

Publisher's Note: MDPI stays neutral with regard to jurisdictional claims in published maps and institutional affiliations.

Copyright: (c) 2021 by the authors. Licensee MDPI, Basel, Switzerland. This article is an open access article distributed under the terms and conditions of the Creative Commons Attribution (CC BY) license (https:/ / creativecommons.org/licenses/by/ $4.0 /)$.

\begin{abstract}
Green regeneration of industrial brownfields (GRIB) is an inevitable choice under the collision of industrial structure adjustment and ecological civilization construction. Due to vegetation destruction and industrial pollution, the integrity and health of the ecosystem in the industrial brownfield have been destroyed and ecological security has become a primary factor in restricting GRIB. In order to explore the impact mechanism of GRIB under ecological security constraints, based on the original data obtained from in-depth interviews with 21 professionals, this study examines the applicability of DPSIR model in GRIB by using the grounded theory method to sort the determinants and explore the impact mechanism of GRIB under ecological security constraints from five dimensions: driving forces (incentive factor), pressure (external factor), state (internal factor), influence (produced comprehensive result), and response (substantive response of human society). Suggestions are made to strengthen the investigation and remediation of environmental pollution in industrial brownfield, cultivate the concept and awareness of green regeneration, and formulate incentive policies. The research conclusions effectively improve the problems existing in the reconstruction of industrial brownfield as well as provide a theoretical basis and targeted reference for the promotion of GRIB.
\end{abstract}

Keywords: industrial brownfield; green regeneration; grounded theory; DPSIR; influencing factors

\section{Introduction}

Industrial brownfields refer to abandoned industrial lands which contain, or may contain, toxic substances or pollutants [1]. With the acceleration of urbanization, many cities have gradually entered the post-industrial era, which has brought problems such as functional degradation and inefficient use of industrial land in cities, resulting in the emergence of a large number of industrial brownfields [2-4]. The reconstruction of industrial brownfield has become the core of urban renewal [5,6]. According to the "National Soil Pollution Survey Communique" jointly issued by the Ministry of Land and Resources in 2014 , over $34.9 \%$ of industrial wasteland was found to be polluted to varying degrees in China. However, investigations and related researches found the simple traditional reform trend of ignoring the environmental health and use experience of industrial brownfields, failed to fully explore its existing resource value (buildings, equipment, and culture, etc.), which leads to a waste of resources to different extents, even health hazards, and lay huge security risks $[5,7,8]$. Meanwhile, due to the lack of supervision and regulation, and the high cost of land remediation, a large number of "toxic" land has entered the land market without effective restoration $[9,10]$. Incidents of physical health damage caused by people living, working or studying in toxic environments have occurred frequently in recent years [5]. Driven by multiple motivations such as reducing construction investment, 
implementing ecological restoration, and protecting industrial civilization, green regeneration has become an inevitable part for the transformation and development of industrial brownfields $[6,11,12]$.

Green regeneration of old industrial brownfields (hereinafter referred to as GRIB) refers to the restoration and protection of resources through adaptive reuse of resources such as land, buildings, equipment, and facilities under the premise of meeting new functional requirements. On the basis of the restoration and protection of the environment, the existing resources should be utilized to the maximum so as to realize the harmonious development of society and nature [8]. At present, some scholars have carried out research on this area. For example, A. Naphade took the renovation of an industrial brownfield site in India as an example, and proposed that the renovation of buildings based on green concepts that can reduce building energy consumption and result in environmentally friendly architecture [13]. G. Zhang emphasized the importance of green regeneration for the redevelopment of industrial brownfields, and discussed the driving factors affecting developers' green regeneration actions by using the expanded TPB model [8].

Compared with the green regeneration of general construction projects, ecological security is the premise and foundation of industrial brownfield redevelopment $[5,6]$. However, the existing studies are mostly limited to the evaluation of green performance of individual buildings, and there are few explorations of green regeneration under ecological security constraints. Therefore, focusing on the perspective of ecological security, to clarify the controlling factors of GRIB, has become a key issue to optimize renovation projects of industrial brownfields and promote sustainable development. Based on in-depth interviews with 21 professionals involved in GRIB as data sources, this paper establishes the theoretical model of influencing factors of GRIB under ecological security constraints and DPSIR model and provides a scientific theoretical basis for guiding and cultivating the development of GRIB.

The rest of this paper is as follows. Part Two summarizes the literature review and DPSIR theory; Part Three introduces the research methods and data sources; On this basis, the data is encoded in Part Four; In Part Five, the results of data coding are discussed and corresponding suggestions are put forward. Conclusions are drawn based on the results of research analysis and enlightenment for future related studies are proposed in Part Six.

\section{Literature Review}

Today, GRIB is an important part of urban renewal, and a large number of scholars have carried out research in this area. For example, Lili, Dong, W. Wei, P. Yunni analyzed the suitability of transforming abandoned industrial buildings into mass innovation spaces and proposed corresponding design strategies [14]. Guo W, Li B, Zhang Y, et al. proposed the use of green technology to revitalize abandoned industrial buildings and implement the corresponding design principles of green energy saving [15]. Krystyna Strumillo analyzed the potential of reusing abandoned industrial buildings and proposed the main strategies, design standards, and implementation scope [16]. Zhang L took the regeneration project of an industrial brownfield site in the Tiexi District of Shenyang as an example and evaluated the overall performance of the brownfield reconstruction area by observing the evolution of energy analysis [17]. Haozhe, $X$ took Baosteel's grand stage renovation as an example to discuss how to use the concept and technology of green buildings in the renovation of abandoned industrial buildings, and provided a basis for effectively realizing building energy conservation and promoting the sustainable development of the ecological environment [18]. Based on the architectural characteristics of abandoned industrial buildings, Wilson proposed the site selection conditions and precautions for the recycling of abandoned industrial buildings, aiming to serve decision-making [19].

According to the existing research literature, GRIB research mainly focuses on the regeneration potential, planning and design, and project decision-making of industrial brownfields, and mainly focuses on quantitative analysis. With the publication of the report entitled "World Commission on Environment and Development" by the United 
Nations, sustainable development has entered the world stage, and research on GRIB has gradually expanded into the context of ecological security. In the area of ecological security, research into industrial brownfields completed by Kolosz, B.W., et al. established a comprehensive redevelopment workflow for the redevelopment program evaluation in industrial brownfield based on ecosystem security [20]. Yang Q. et al. used the energyecological footprint model to quantitatively analyze the ecological security status of the industrial brownfield in Northeast China from the time series [21]. Su, H., \& Lei, J. analyzed the characteristics of spatial form evolution in industrial brownfield based on economic and ecological benefits and put forward relevant suggestions for the reconstruction of the industrial brownfield in Baotou City, Inner Mongolia, China [22]. The question of how to better transform the industrial brownfield on the premise of restoring ecological security, so that it cannot only meet the new functions of the abandoned industrial buildings, but also protect the surrounding sites and ecological environment, requires us to carry out deeper thinking and build upon the described foundation of research.

In measuring the environment and sustainable development, the PSR model proposed by the United Nations Economic Cooperation and Development Organization [23], the DSR model proposed by the United Nations Commission on Sustainable Development [24] and the DPSIR model proposed by the European Environment Bureau [25] have been widely recognized. In view of this, this paper focuses on the controlling factors of GRIB from the perspective of ecological security. On the basis of referring to the evaluation models commonly used by foreign scholars in the construction of environmental economic index system, this paper attempts to apply the DPSIR model to GRIB research, and analyze and discuss the controlling factors of GRIB from five dimensions: driving forces, pressure, state, influence, and response. As the core goal of GRIB is to achieve the harmonious coexistence of environment and resources, its essence is to achieve the mutual benefit and symbiosis between GRIB and ecological security in a regional area [26], not only a good construction of ecological security, but also the smooth development of GRIB [27]. The DPSIR model is the mainstream of current ecological security research. Based on this model, a new chain closed-loop index system framework can be established, which can clearly reflect the internal causal logic relationship of research objects. Compared with other ecological security index system models, GRIB includes five attribute elements: driving forces, pressure, state, impact, and response, which fully conform to the theoretical model of the DPSIR system. Therefore, this paper selects the framework of the DPSIR model and uses grounded theory as a qualitative research method to design an interview outline from the five dimensions of driving forces, pressure, state, impact, and response, to study the influencing factors of GRIB under ecological security constraints, and finally establish a theoretical model for the influencing factors of GRIB under the constraints of ecological security and the DPSIR model. It provides a basis for effectively improving the problems existing in GRIB, ensuring the security, use and promotion of GRIB development.

\section{Study Methods and Data Collection}

\subsection{Methodology}

From the perspective of qualitative research, grounded theory is used in this paper to identify the influencing factors of GRIB under ecological security constraints. The specific process is shown in Figure 1. The grounded theory is based on the symbolic interaction theory [28], which was first jointly proposed by two scholars, Barney Glaser of the University of Chicago and Anselm Strauss of Columbia University [29]. For our research on GRIB, first, we designed open-ended questions and in-depth interviews were conducted with professionals involved in GRIB to obtain the original interview data. Then, the collected data was coded, and finally a theoretical model of influencing factors of GRIB under ecological security constraints was constructed. 


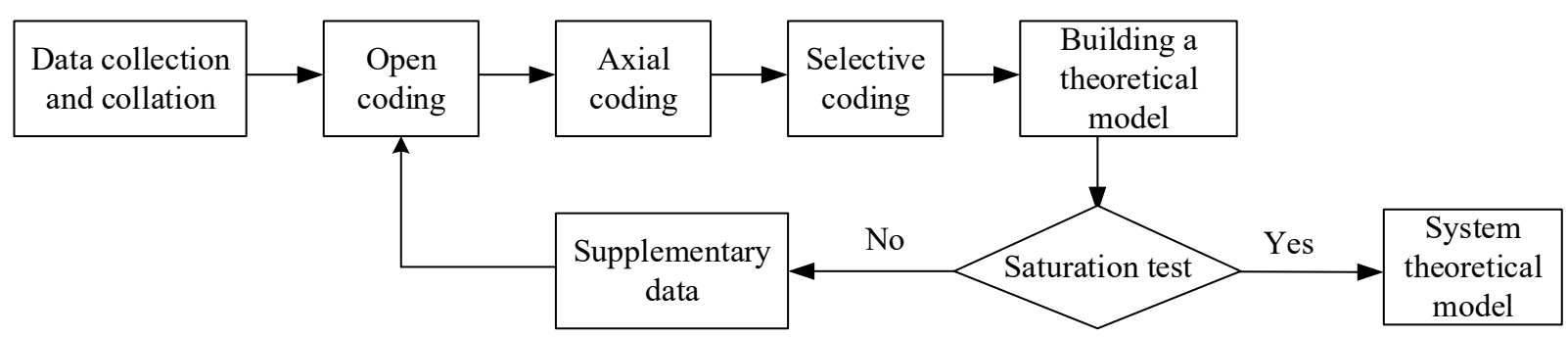

Figure 1. Specific Process of Grounded Theory.

\subsection{Data Collection}

In order to ensure that the interviewees understand the characteristics of GRIB, the data is obtained by designing interview outlines and an in-depth interview. In addition, because this paper studies GRIB from the perspective of ecological security, the interview outline mainly refers to the DPSIR model used for ecological environment assessment, and is designed from the five dimensions of driving force $D$, pressure $P$, state $S$, impact $I$ and response $\mathrm{R}$. The introduction of the interview outline explains the concepts of "green building" and "green regeneration" to the interviewees to ensure that they understand the relationship between them. In addition, in order to improve the generality and accuracy of the study, cities with a large number of industrial brownfields in eastern, western, southern and northern China are selected for investigation, as shown in Figure 2. The geographical and cultural environment of these cities are different, so the nature of the industrial brownfield is different. The interview samples include state-owned enterprises and private enterprises. The interviewees are mainly individuals who participate in or are familiar with GRIB projects, including government personnel, managers of industrial brownfields, workers, and the surrounding people. Prior to the interview, a background check was conducted to ensure all interviewees have been participated in the whole process of at least one regeneration project and were clear about the problems existing in regeneration.

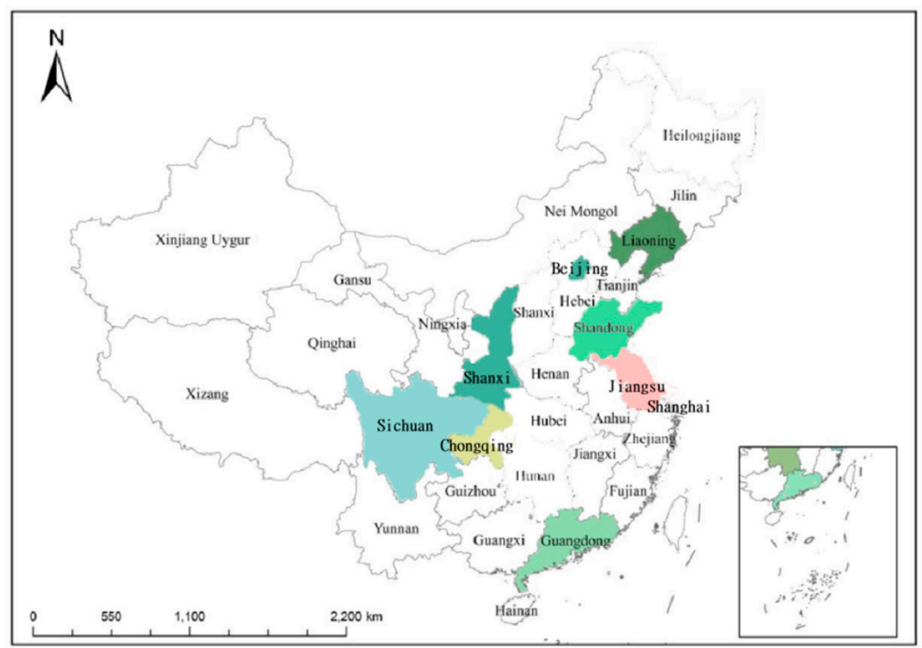

Figure 2. Data Source Distribution.

The interview can be divided into the following three steps: firstly, the interview outline is designed, and the corresponding prompt information is set for the questions, so as to better guide the respondents to answer; Secondly, the GRIB project in Xi'an is selected to conduct a preliminary survey. Based on the feedback, the questions and prompt information are adjusted, then a formal interview outline is formulated; Finally, through one-to-one site interview professionals who participate in or are familiar with GRIB, the formal research data is collected. After the classification of interviews, 25 
interviews were completed, of which four interviews were excluded due to unsatisfactory quality (including invalid content and missing data). Finally, 21 effective interviews were obtained. The basic information of interviewees and the interview outline are shown in Tables 1 and 2 respectively.

Table 1. Demographics of Respondents (total $=21$ ).

\begin{tabular}{cccc}
\hline Basic Information & Classification & Numbers & Percentage (\%) \\
\hline \multirow{2}{*}{ Sex } & Male & 12 & 57.1 \\
& Female & 9 & 42.9 \\
\hline \multirow{2}{*}{ Age } & $20 \sim 30$ & 4 & 19.0 \\
& $30 \sim 40$ & 9 & 42.9 \\
& $40 \sim 50$ & 5 & 23.8 \\
\multirow{3}{*}{ Education Level } & 50 above & 3 & 14.3 \\
& Junior College (including high school) & 5 & 9.5 \\
& Undergraduate & 10 & 23.8 \\
& Master degree or above & 4 & 47.6 \\
& Government Personnel & 6 & 19.1 \\
\hline \multirow{3}{*}{ Occupation } & Managers & 8 & 28.6 \\
& Workers & 4 & 38.1 \\
& The Masses & 3 & 19.0 \\
& &
\end{tabular}

Table 2. Interview Outline of Influencing Factors of GRIB.

\section{Interview Steps}

Step 1:

Confirm if you agree to renovate industrial brownfield in accordance with green building requirements?

\section{Interview Outline}

Q1: Do you think the industrial brownfield can be renovated according to the requirements of green building?

(If the answer is "Yes", proceed to Q2. If the answer is "No", proceed to Step 4)

Q2: In your opinion, what are the advantages of rebuilding industrial brownfield in accordance with the requirements of green buildings?

Q3: Have you personally participated in the process of green regeneration in industrial brownfields?

(If the answer is "Yes", proceed to Step 2. If the answer is "No", proceed to Step 3)

Q4: In your opinion, what are the main aspects of the reconstruction of the industrial brownfields? Which aspects do you think should be carried out in accordance with the requirements of green buildings?

Q5: Did you encounter any difficulties in the GRIB process? How were these problems finally solved?

Step 2:

1. Learn details about the process of GRIB.

2. Identify the factors that lead to slow and inefficient growth of GRIB.

$$
\text { you help? }
$$

Q6: Have the government and society offered any help to GRIB? In what ways did

Q7: Do you know what the people around you think about GRIB? (If the answer is "No", proceed to Q8)

Q8: Do you think that GRIB has an impact on regional economic development and regional image? What are those specific effects?

(If the answer is "No", proceed to Q9)

Q9:What do you think has driven the development of GRIB?

Q10: What problems do you think GRIB has? What factors have affected the development of GRIB?

Q11: Do you have any better suggestions for GRIB?

Step 3:

Identify potential interviewees.

Step 4:

Learn more details about the reasons for not agreeing to renovate industrial brownfield in accordance with green building requirements.
Q12: Do you have any other cases or projects involving GRIB?

(If the answer is "Yes", repeat Step 2. If the answer is "No", the interview is over.)

Q13: In GRIB, have you considered such factors as low-carbon, energy-saving, environmental protection and green? In what aspects are these factors considered?

Q14: Why do you think that industrial brownfield can not be renovated in accordance with the requirements of green buildings? 


\section{Data Analysis}

Data analysis mainly involves data classification and coding [30]. In the classical research method of grounded theory, coding is mainly a comparison between continuous events and event concepts, thus forming more categories and conceptual features [31]. In addition, Strauss and Corbin summarized three coding processes related to theoretical sampling, namely open coding, axial coding and selective coding [32]. In this study, NVivo11 software was used for data coding. Before coding, the interview information was first sorted and classified, and then the organized interview data was imported into the software for standardized information management and coding.

\subsection{Open Coding}

Open coding is the first step of the grounded theory. This stage mainly classifies and abstracts the interview data and is the preliminary coding process for researchers to read and analyze the data [33]. To be specific, initial concepts are given to the original statements collected in the interview, and then the initial concepts are recombined through continuous analysis, sorting and summary to form a more general category. This process requires researchers' impartial attitude to encode interview data and make objective definitions [34], which is a deep understanding and analysis of interview data. In addition, open coding is mainly based on several principles: first, to be as detailed as possible without missing any key information; second, analyze the data line by line, and continuously explore the answers to the questions; third, the original statements of interviewees should be used as much as possible in the coding process, especially those that can be set as nodes [35]; finally, each node is named according to the original phrases of the interviewees or the phrases defined by the researcher himself [36]. This article analyzes the influencing factors of GRIB under ecological security constraints. A total of 256 original sentences were collected in interview. The NVivo11 software was used to encode original data with high frequency and strong representative, and finally 70 initial concepts, denoted by and, were extracted fromd the original sentences. Thend the initial concept is continuously analyzed, sorted and summarized, and recombined to get 18 initial categories which are represented by AN. Table 3 is a partial example of extracting initial concepts, and Table 4 is the final result of open coding.

Table 3. Partial Examples of Extracting Initial Concepts.

\section{Initial Concepts \\ a0 market competition, a1 industry elimination, a2 public opinion, a3 mass advocacy, a4 peer selection}

a5 green regeneration technology, a6 technology innovation, a7 personnel training, a8 unification and standardization

a9 industrial structure adjustment, a10 compression of traditional industries, a11 development of urban industries, a12 scale restrictions, a13 land structure adjustment

a14 production mode is extensive, a15 groundwater is polluted, a16 heavy metal content, a17 soil pollution
Original Statements of Interviewees

The surrounding enterprises have begun to use green technology, the masses are also very advocated, the effect is also good, we cannot lag behind, otherwise we will be eliminated by the industry; the original production method caused environmental pollution, brought damage to the surrounding environment, which was widely criticized by the public.

The developers pay attention to the transformation of industrial brownfield by using green regeneration technology, encourage technological innovation and pay

attention to personnel training; The government formulates corresponding standards for GRIB and constantly improves them. Green regeneration technology is gradually unified and standardized.

Adjust the industrial structure, vigorously reduce the traditional industrial enterprises with large land occupation and heavy pollution, and free up land for the development of urban industries with small land occupation and high output value; The reduction of land price leads to the increase of land structure and limits the scale of industrial land.

Due to the extensive production mode in the early stage, the sewage treatment is not in place, and the groundwater is polluted; The results of soil pollution survey showed that the content of toxic and harmful substances in some industrial areas exceeded the standard, and the soil environmental situation was not optimistic.

Regional land resources and the ability to support human activities are limited. 
Table 4. Open Coding.

\begin{tabular}{|c|c|}
\hline Initial Category & Initial Concept \\
\hline A1 market demand & a0 market competition/a1 industry elimination/a2 public opinion/a3 mass advocacy/a4 peer selection \\
\hline $\begin{array}{l}\text { A2 technology and } \\
\text { talent }\end{array}$ & $\begin{array}{c}\text { a5 green regeneration technology support/a6 technology innovation/ } 7 \text { talent training/a8 unification } \\
\text { and standardization }\end{array}$ \\
\hline $\begin{array}{l}\text { A3 industry } \\
\text { transformation }\end{array}$ & $\begin{array}{l}\text { a9 industrial structure adjustment/a10 compression of traditional industries/a11 development of urban } \\
\text { industries/a12 scale restriction/a13 land structure adjustment }\end{array}$ \\
\hline $\begin{array}{l}\text { A4 environmental } \\
\text { pollution }\end{array}$ & a14 extensive production mode/a15 groundwater pollution/a16 heavy metal content/a17 soil pollution \\
\hline $\begin{array}{l}\text { A5 land resources } \\
\text { carrying capacity }\end{array}$ & a18 land resources/a19 supporting capacity \\
\hline A6 economic benefits & a20 land appreciation/a21 sustainable return/a22 income increase \\
\hline $\begin{array}{l}\text { A7 original enterprise } \\
\text { resettlement }\end{array}$ & a23 employee placement/a24 compensation not in place/a25 wage arrears \\
\hline A8 investment cost & a26 high cost/a27 difficult construction/a28 Limited construction conditions \\
\hline A9 own attributes & a29 land use attribute change/a30 industrial nature/a31 area coverage/a32 geographical location \\
\hline $\begin{array}{l}\text { A10 structure and } \\
\text { function }\end{array}$ & $\begin{array}{l}\text { a33 single function/a34 mechanical segmentation/a35 lack of public space/a36 isolated form/a37 } \\
\text { uncoordinated with surrounding buildings }\end{array}$ \\
\hline A11 plant planning & a38 land planning/a39 unreasonable land distribution/a40service facilities/a41 diversified sharing \\
\hline $\begin{array}{l}\text { A12 regional } \\
\text { development }\end{array}$ & $\begin{array}{l}\text { a42 regional economy/a43 perfect industrial chain/a44 employment opportunities/a45 history and } \\
\text { culture/a46 industrial context continuation }\end{array}$ \\
\hline A13public interest & $\begin{array}{l}\text { a47 people's satisfaction/a48 people's health/a49 optimizing regional environment/a50 people's } \\
\text { support/a51 quality of life }\end{array}$ \\
\hline A14 green ciognition & $\begin{array}{c}\text { a52 low awareness/a53 little understanding of green building/a54green awareness/a55green } \\
\text { regeneration way }\end{array}$ \\
\hline A15 social supervision & $\begin{array}{l}\text { a56 environmental monitoring/a57 information transparency/a58 department supervision/a59 quality } \\
\text { assessment/a60 transparent management }\end{array}$ \\
\hline A16 financial subsidy & a61 tax incentives/a62 capital subsidies/a63 low interest loans \\
\hline $\begin{array}{l}\text { A17 system } \\
\text { specification }\end{array}$ & $\begin{array}{c}\text { a64 indicators are different/a65 lack of provisions/a66 current specifications cannot meet/a67 is lack } \\
\text { of standardization }\end{array}$ \\
\hline A18 risk control & a68 develop investigation system for hidden danger/a69 risk control measures \\
\hline
\end{tabular}

\subsection{Axial Coding}

Axial coding is the second step of grounded theory. This stage is to discover and establish the relationship between concept and sub-category, and sub-category and main category [37] which includes the causal relationship, structural relationship and functional relationship, etc. In axial coding, only one subcategory can be deeply analyzed each time to discover the surrounding relations [33].

Therefore, the main purpose of axial coding is to clarify the relationship between each sub-category [38] and establish a more abstract domain level, namely, the main category. The stage of exploring the main category is to re-divide the 18 initial categories obtained from the open coding around the research topic, and finally determine the main five categories, namely driving forces, press, state, influence and response. Table 5 displays the final results of the axial coding. 
Table 5. Results of the Axial Coding.

\begin{tabular}{|c|c|}
\hline Initial Category & Main Category \\
\hline $\begin{array}{c}\text { Market demand } \\
\text { Technology and talent } \\
\text { Industrial transformation } \\
\text { Economic benefit }\end{array}$ & Driving forces \\
\hline $\begin{array}{l}\text { Land resources carrying capacity } \\
\text { Environmental pollution } \\
\text { Original enterprise resettlement } \\
\text { Investment cost }\end{array}$ & Pressure \\
\hline $\begin{array}{l}\text { Own attributes } \\
\text { Structure functions } \\
\text { Plant planning }\end{array}$ & State \\
\hline $\begin{array}{l}\text { Public interest } \\
\text { Regional development } \\
\text { Green cognition }\end{array}$ & Influence \\
\hline $\begin{array}{l}\text { Social supervision } \\
\text { Financial subsidy } \\
\text { System specification } \\
\text { Risk control }\end{array}$ & Response \\
\hline
\end{tabular}

\subsection{Selective Coding}

Selective coding is the third step of grounded theory. This stage is mainly to identify the core category, and systematically link the core category with the main category. The information collected is then used to confirm this kind of link which will be further refined by forming theories [39]. In addition, the core category must be universal and instructive, so that most research results can be limited in a broad theoretical scope [37]. The general core category mainly has the following characteristics: first, it must be located in the center and connected with other categories; secondly, in the coding process, it appears with the most frequency; finally, the connection between it and other categories is spontaneous [40]. The core category of this study is the influencing factors of GRIB under the ecological security constraints. Based on this core category, the structural relationship between GRIB and the main categories of driving forces, pressure, state, influence and response is analyzed. As shown in Table 6, it can be seen from the table that driving forces, pressure, state, influence and response all directly affect the development of GRIB.

Table 6. The Relation Structure between Main Categories.

\begin{tabular}{clc}
\hline Relation & Relation Structure & Connotation of Relation Structure \\
\hline Driving forces $\rightarrow$ GRIB & Causal Relationship & Driving forces expedites the development of GRIB \\
\hline Pressure $\rightarrow$ GRIB & Causal Relationship & Pressure hinders the development of GRIB \\
\hline State $\rightarrow$ GRIB & Causal Relationship & State has a positive impact on the development of GRIB \\
\hline Influence $\rightarrow$ GRIB & Causal Relationship & Influence promotes the development of GRIB \\
\hline Response $\rightarrow$ GRIB & Causal Relationship & Response has a positive impact on the development of GRIB \\
\hline
\end{tabular}

\subsection{Saturation Test}

The mark of the completion of the grounded theory construction model is to achieve theoretical saturation. When there is a saturation point of data and data collection is no longer helpful to explain the object of research, the grounded theory research reaches saturation [41]. After the coding above, this paper randomly selected five more professionals involved in GRIB for interviews, and found no new categories and relationships. Therefore, 
the influencing factor model of GRIB established in this paper has reached saturation in theory.

\section{GRIB Influencing Factors Analysis}

5.1. GRIB Influencing Factors Analysis of GRIB

\subsubsection{Driving Forces}

Driving forces is the incentive factors of GRIB, including four initial categories of market demand, technology and talent, industrial transformation, and economic benefit. First of all, market demand is an external driving factor for green regeneration, and market competition and public opinion pressure will promote the development of GRIB. Secondly, the rise of green technology makes green regeneration become the mainstream of transformation in industrial brownfields. Meanwhile, green technology and professionals promote the development of GRIB. Finally, industrial transformation and economic benefits are powerful driving forces of GRIB. Industrial transformation will bring about economic benefits and further promote the development of GRIB.

\subsubsection{Pressure}

Pressure is an external factor of GRIB, including four initial categories of land resources carrying capacity, environmental pollution, original enterprise resettlement, and investment cost. First of all, although GRIB can make use of the existing building structures and materials, the existing structures in some industrial brownfields will restrict the construction conditions, increasing the construction difficulty and the investment cost. Secondly, the level of land resources carrying capacity will affect the effect of GRIB in the area. The land resources carrying capacity represents the limit of the supporting capacity of land resources to human activities in a certain area. GRIB must remain within the limits of land carrying capacity. Then, effective remediation measures need to be taken in the industrial brownfield with groundwater pollution, soil pollution, air pollution and other environmental pollution. Pollution remediation in GRIB is a process with complex technology and high cost. Finally, for the resettlement of employees in the original enterprise, arrears of wages in early times or insufficient economic compensation will slow down or even stop the progress of GRIB, forming potential threats to the development of GRIB.

\subsubsection{State}

State is an internal factor in implementing green regeneration, including three initial categories: it's own attributes, structure functions and plant planning in industrial brownfields. The attributes of the industrial brownfield determines how easy it is to implement green regeneration. For example, the nature of the ownership of industrial brownfield, the developers of private capital mainly focus on economic benefits; However, the developers that match the government's dominance or participation are more likely to consider the problem from the perspective of public interests, so as to realize a benign interactive development between the production mode of the industrial brownfield and the ecological environment. Structure functions and plant planning can also contribute to the development of the GRIB. The traditional industrial brownfield is mainly based on production and services, and lack of life functions. Green regeneration can not only replace the previous single mechanical division with functional mixing to form a continuous and hierarchical spatial structure, but also alleviate the impact of industrial pollution on the ecological environment in the spatial layout.

\subsubsection{Influence}

Influence is a comprehensive result produced by GRIB, including three initial categories of public interest, regional development and green cognition. The traditional industrial brownfield has an advantageous geographical location, surrounded by mostly residents' living and working places with a dense population. Therefore, the public interest is an important factor in influencing the GRIB. Secondly, the government-led old industrial 
areas will consider the impact on regional development from the perspective of public interests, including the regional economy, employment opportunities and historical and cultural protection. In addition, for industrial brownfields with industrial cultural value, the protection of historical and cultural heritage is a key factor that affects the choice of transformation methods for old industrial areas. Finally, green awareness is a guiding factor for the development of GRIB. Whether people have a full clear understanding of green regeneration methods will affect the developers' acceptance of green regeneration methods to a certain extent.

\subsubsection{Response}

Response is the substantive response of human society to the way of GRIB, which includes four initial categories: social supervision, risk control, financial subsidies and system specification. Social supervision leads GRIB. The soil test results and environmental quality assessment reports of industrial brownfield are made public, which helps to take reasonable risk control measures before reconstruction to improve the effect of GRIB. Secondly, financial subsidies can stimulate the enthusiasm of developers, alleviate the financial pressure of GRIB, and have a positive impact on the transformation of industrial brownfield by green regeneration. Finally, when the industrial brownfield is transformed into buildings for other purposes in the later stage, the existing system specifications cannot cover the particularity of the industrial brownfield due to the differences in fire protection, HVAC and other indicators of different buildings. The perfection of the system specifications will help to the standardization of GRIB and promote its the development.

\subsection{GRIB Construction of the Theoretical Model}

Based on the analysis of the above influencing factors, it is concluded that the influencing factors of GRIB are mainly divided into five categories: driving forces, pressure, state, influence and response. On this basis, a theoretical model of influencing factors of GRIB under ecological security constraints is constructed, as shown in Figure 3.

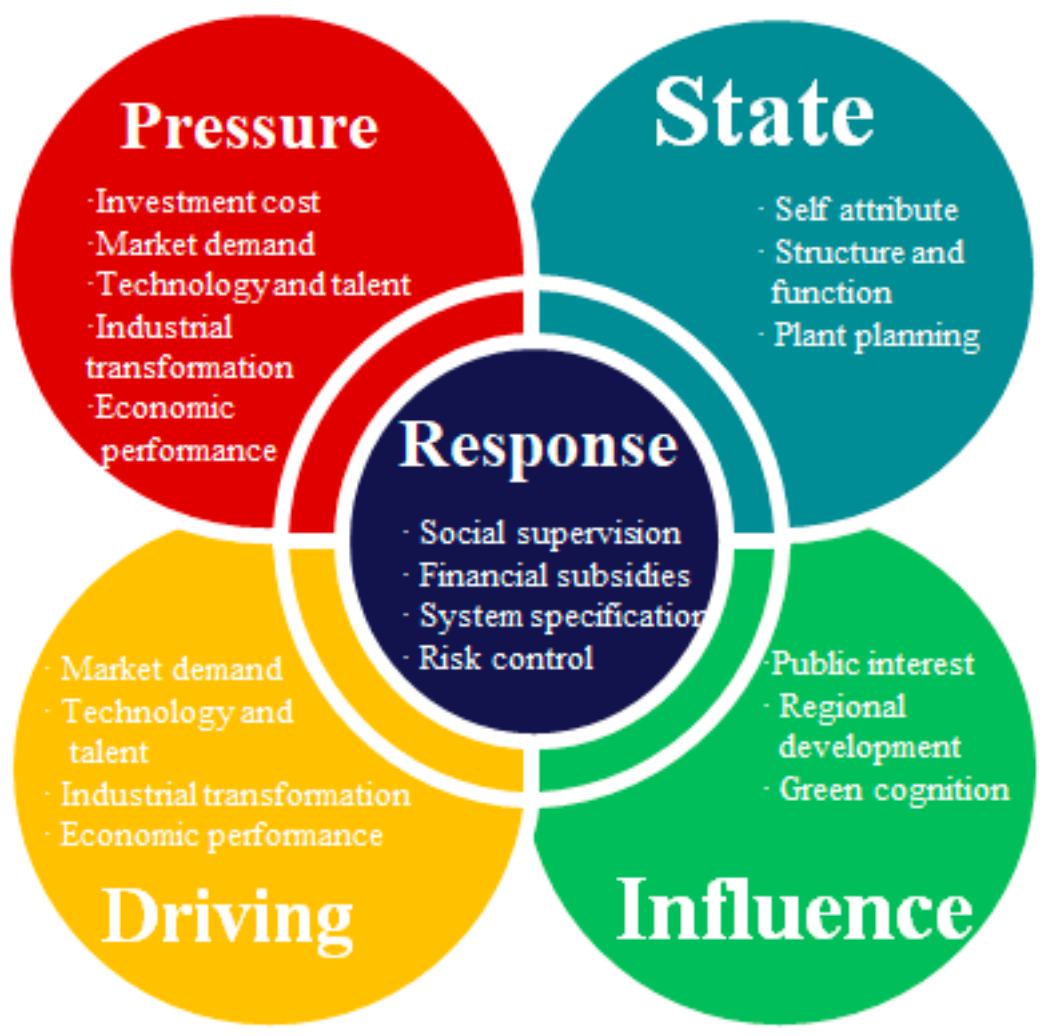

Figure 3. Theoretical Model of Influencing Factors of GRIB. 
In the process of exploring the influencing factors of GRIB through the grounded theory, the interaction between the main categories is also explored, which is linked to the development of GRIB, and the DPSIR structural model of GRIB is constructed, as shown in Figure 4.

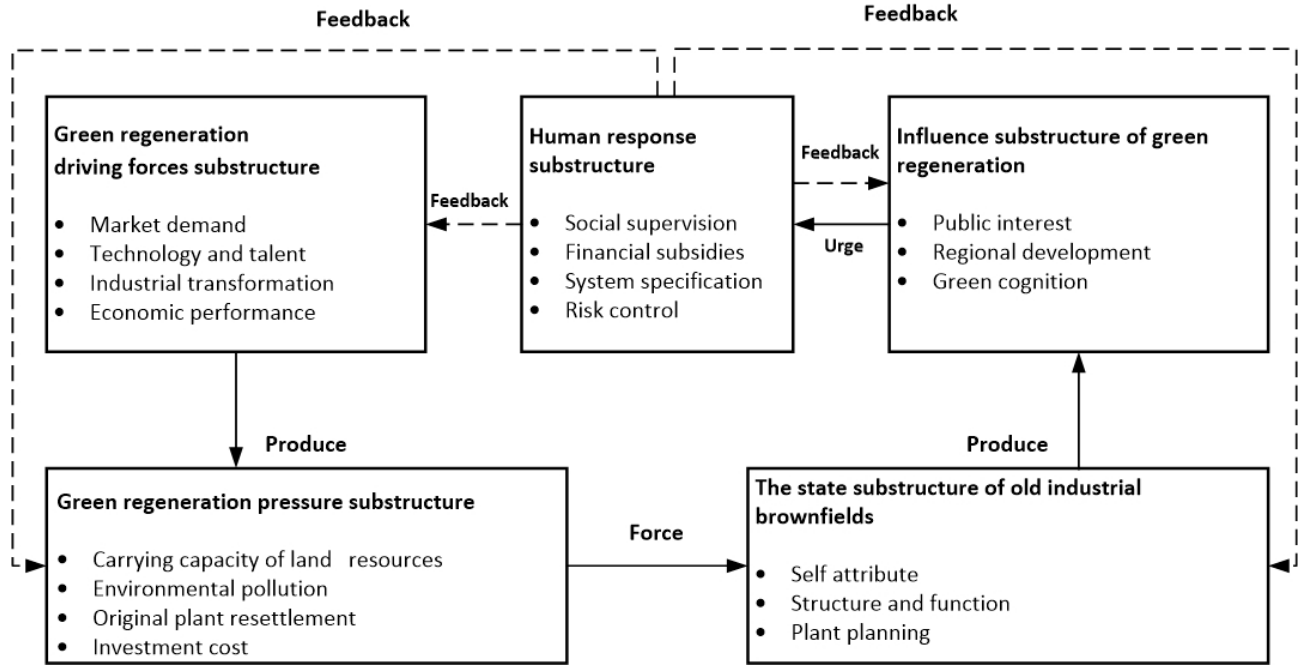

Figure 4. DPSIR Structural Model of GRIB.

\subsection{The Policy Implication for Development of GRIB}

In this paper, through in-depth interviews with 21 professionals participating in GRIB, the influencing factors of GRIB under ecological security constraints are analyzed. Based on the DPSIR model commonly used in evaluating ecological security, the influencing factors are divided from five dimensions of driving forces, pressure, state, influence and response. Research results show that Driving forces includes four initial categories of market demand, Technology and talent, industrial transformation and economic benefit. Pressure includes four initial categories of land resources carrying capacity, environmental pollution, original enterprise resettlement and investment cost. State includes three initial categories of own attributes, structure functions and plant planning. Influence includes three initial categories of public interest, regional development and green cognition. Response includes four initial categories of social supervision, financial subsidy, system specification and risk control. On this basis, the following suggestions are made to promote the development of GRIB for reference by relevant decision makers.

First, the government departments should strengthen the investigation and remediation of environmental pollution in the industrial brownfields, so as to ensure a better development of GRIB under ecological security constraints. It is found that some industrial brownfield have environmental pollution problems such as groundwater pollution and heavy metal content exceeding the standard in the field environmental assessment, which seriously damage the ecological environment of industrial brownfield. Ecological security is the premise and key to restrict the development of GRIB. Therefore, government departments should strengthen investigation and management in industrial brownfields. Secondly, it is necessary to reduce the cost of adopting green technology and related measures or increase the profit ratio of later operation because the developers will consider their own economic benefits when making renovation decisions, and the pursuit of maximum benefits is a fundamental starting point of their decision-making. Finally, it is more necessary for government departments to provide clearer, simplified and open policies on the development of GRIB in terms of policies, formulate unified standards for green regeneration technology, regulate green regeneration behaviors, and guide the smooth development of green regeneration in industrial brownfields, so that there are rules to follow. 
Second, developers must cultivate the concept and awareness of green regeneration and raise the level of awareness of green regeneration. Most of the managers and developers in industrial brownfield are relatively in senior age, the transformation model is more restricted by their traditional concepts, and the awareness of green regeneration is relatively weak. The developer is the implementer of GRIB, and their green regeneration behaviors can effectively promote the development of GRIB projects, improve the regional environment and redevelopment effects [42,43]. Therefore, to promote the development of GRIB, it is necessary to strengthen the publicity of green regeneration behaviors, cultivate developers' awareness of green regeneration, recognize the advantages of green regeneration, and change the traditional transformation modes in industrial brownfields. Only developers who have experienced the benefits of GRIB will be more willing to consider adopting this approach.

Third, the government should formulate incentive-oriented policies to encourage the use of green regeneration methods to transform industrial brownfields. Policy support is mainly manifested in two aspects: financial subsidies and reward and punishment mechanism. The financial subsidy policy has a positive impact on the development of GRIB, which provides a certain of financial support to developers and helps them share the pressure when adopting green regeneration mode for the reconstruction in industrial brownfields and ensures the developers to obtain benefits. At the same time, it should also focus on the city image, ecological security and land revitalization. In addition, a perfect reward and punishment mechanism should be formulated to regulate, encourage and stimulate developers to adopt green regeneration methods. In the process of supervision, the government can give different degrees of rewards to the industrial brownfield that have been transformed with satisfied effect, so as to enhance the enthusiasm of developers for the transformation in industrial brownfield by means of green regeneration.

\subsection{Research Limitations}

The research in this paper still has some limitations, which need to be solved in the future research. First of all, because the data in this paper is obtained through in-depth interviews, the selection of the interviewees and the processing of the data will involve a certain degree of subjective opinions and limitations of the researchers. Secondly, the reliability of the theoretical model of influencing factors of GRIB under the ecological security constraints and the DPSIR structural model constructed in this paper need to be further tested by empirical research. Finally, the research data of this paper is collected in the context of Chinese culture. Due to the differences in the environment, cultural backgrounds and policies of different countries, whether the research conclusions of this paper are applicable to other countries has not been confirmed. Therefore, GRIB cases in other countries or regions should be fully considered in the subsequent studies.

\section{Conclusions}

This study innovatively applied DPSIR model to the exploration of the influencing factors of industrial brownfield green regeneration projects, providing a more comprehensive account of the determinants toward GRIB. Through in-depth interviews with 21 professionals involved in GRIB, the research applies the grounded theory method to reveal the impact mechanism of GRIB under ecological security constraints. The influencing factors of GRIB were clarified from five dimensions: driving forces (incentive factor), pressure (external factor), state (internal factor), influence (comprehensive effect) and response (substantive response). This study has made a certain contribution to the theoretical research and practice of regeneration in industrial brownfield: First of all, this paper analyzes the influencing factors of GRIB from the perspective of ecological security, which provides a new way for future research on GRIB. Secondly, the DPSIR structure model, which is commonly used in evaluating ecological security, is applied to the research of GRIB to establish the DPSIR structure model of GRIB, which is conducive to clarify the key factors affecting GRIB and enhance the understanding and support of developers to GRIB. Finally, 
research conclusions in this paper can help the government formulate relevant policies to promote the development of GRIB, ensure the security of the project and optimize the transformation result.

Author Contributions: Conceptualization, G.Z.; formal analysis, F.Y., Y.Z.; writing-original draft, F.Y.; writing—review and editing, F.Y., Y.Z., G.Z.; funding acquisition, Y.Z. All authors have read and agreed to the published version of the manuscript.

Funding: This research was funded by the National Natural Science Foundation of China, grant numbers 51808424, 51677879; the Shaanxi Provincial Basic Research Program of Natural Science, grant number 2020JQ-690.

Institutional Review Board Statement: Not applicable.

Informed Consent Statement: Informed consent was obtained from all subjects involved in the study.

Data Availability Statement: The data presented in this study are available on request from the corresponding author. The data are not publicly available due to privacy or ethical restrictions.

Acknowledgments: We would like to thank Fang Qiao for English language editing support.

Conflicts of Interest: The authors declare no conflict of interest.

\section{References}

1. U.S. EPA. Brownfield Economic Redevelopment Initiative; US Environmental Protection Agency, Solid Waste and Emergency Response: Washington, DC, USA, 1997.

2. Naing, Y.M.; Nitivattananon, V.; Shipin, O.V. Green Roof Retrofitting: Assessment of the Potential for Academic Campus. Eng. J. Thail. 2017, 21, 18. [CrossRef]

3. Mohd-Rahim, F.A.; Pirotti, A.; Keshavarzsaleh, A.; Zainon, N.; Zakaria, N. Green construction project: A critical review of retrofitting awarded green buildings in Malaysia. J. Des. Built Environ. 2017, 17, 11-26. [CrossRef]

4. Shi, J.; Xu, T. Efficiency evaluation of industrial parks land in Yangtze River Urban Agglomerations based on VRS-DEA Model and Malmquist Productivity Index. Resour. Sci. 2017, 29, 1026-1036.

5. Wu, Q.; Zhang, X.; Liu, C.; Chen, Z. The de-industrialization, re-suburbanization and health risks of brownfield land reuse: Case study of a toxic soil event in Changzhou, China. Land Use Policy 2018, 74, 187-194. [CrossRef]

6. Zhang, Y.; Wang, C.; Tian, W.; Zhang, G. Determinants of purchase intention for real estate developed on industrial brownfields: Evidence from China. J. Hous. Built Environ. 2020, 35, 1261-1282. [CrossRef]

7. Ma, Z.; Cooper, P.; Daly, D.; Ledo, L. Existing building retrofits: Methodology and state-of-the-art. Energy Build. 2012, 55, 889-902. [CrossRef]

8. Zhang, G.; Zhang, Y.; Tian, W.; Li, H.; Guo, P.; Ye, F. Bridging the Intention-Behavior Gap: Effect of Altruistic Motives on Developers' Action towards Green Redevelopment of Industrial Brownfields. Sustainability 2021, 13, 977. [CrossRef]

9. Ren, W.; Xue, B.; Geng, Y.; Sun, L.; Ma, Z.; Zhang, Y.; Mitchell, B.; Zhang, L. Inventorying heavy metal pollution in redeveloped brownfield and its policy contribution: Case study from Tiexi District, Shenyang, China. Land Use Policy 2014, 38, 138-146. [CrossRef]

10. Ren, W.; Geng, Y.; Ma, Z.; Sun, L.; Xue, B.; Fujita, T. Reconsidering brownfield redevelopment strategy in China's old industrial zone: A health risk assessment of heavy metal contamination. Environ. Sci. Pollut. Res. 2015, 22, 2765-2775. [CrossRef] [PubMed]

11. Pittau, F.; Bande, L.; Passera, A.; Beacco, D.; Fumagalli, C.; de Angelis, E. Brownfields regeneration as a smart growth option and building technologies: The case study of "La Goccia Di Bovisa" in Milano. In Proceedings of the 5th Brunei International Conference on Engineering \& Technology, Bandar Seri Begawan, Brunei, 1-3 November 2014; IET: London, UK, 2015.

12. Glumac, B.; Han, Q.; Schaefer, W.; van der Krabben, E. Negotiation issues in forming public-private partnerships for brownfield redevelopment: Applying a game theoretical experiment. Land Use Policy 2015, 47, 66-77. [CrossRef]

13. Naphade, A.; Sharma, A.; Chani, P.S.; Garg, P. Green Building Retrofit for the Library of Indian Institute Technology, Roorkee. J. Inst. Eng. India Ser. A 2013, 94, 35-42. [CrossRef]

14. Dong, L.; Wang, W.; Peng, Y. Suitability design strategy of the renovation of old industrial building to maker space. Ind. Constr. 2019, 49, 31-37, 79 .

15. Guo, W.; Li, B.; Zhang, Y.; Schnabel, M.A. The research of green reuse on old industrial building: A case study of Changchun FAW. In IOP Conference Series: Earth and Environmental Science; IOP Publishing: Bristol, UK, 2020; Volume 567, p. 012030.

16. Strumiłło, K. Adaptive Reuse of Buildings as an Important Factor of Sustainable Development. In Advances in Human Factors and Sustainable Infrastructure; Charytonowicz, J., Ed.; Springer International Publishing: Cham, Switzerland, 2016; pp. 51-59.

17. Zhang, L.; Geng, Y.; Dong, H.; Zhong, Y.; Fujita, T.; Xue, B.; Park, H.-C. Emergy-based assessment on the brownfield redevelopment of one old industrial area: A case of Tiexi in China. J. Clean. Prod. 2016, 114, 150-159. [CrossRef]

18. Xiong, H. Study on the reconstruction of old industrial buildings under passive technology-A case of Baogang grand stage. Urban. Archit. 2019, 16, 129-133. 
19. Wilson, C. Adaptive Reuse of Industrial Buildings in Toronto, Ontario: Evaluating Criteria for Determining Building Selection. Master's Thesis, Queen's University, Kingston, ON, Canada, 2010.

20. Kolosz, B.W.; Athanasiadis, I.N.; Cadisch, G.; Dawson, T.P.; Giupponi, C.; Honzák, M.; Martinez-Lopez, J.; Marvuglia, A.; Mojtahed, V.; Ogutu, K.B.Z.; et al. Conceptual advancement of socio-ecological modelling of ecosystem services for re-evaluating brownfield land. Ecosyst. Serv. 2018, 33, 29-39. [CrossRef]

21. Yang, Q.; Lu, C.P.; Zhou, F.; Geng, Y.; Jing, H.S.; Ren, W.X.; Xue, B. An emergy-ecological footprint model based evaluation of ecological security at the old industrial area in Northeast China: A case study of Liaoning Province. Ying Yong Sheng Tai Xue Bao 2016, 27, 1594-1602. [PubMed]

22. Su, H.; Lei, J. The study of spatial form evolution and remodeling of old industrial area-The case of inner Mongolia Baotou. Appl. Mech. Mater. 2013, 409-410, 847-850. [CrossRef]

23. Wolfslehner, B.; Vacik, H. Mapping indicator models: From intuitive problem structuring to quantified decision-making in sustainable forest management. Ecol. Indic. 2011, 11, 274-283. [CrossRef]

24. Ness, B.; Anderberg, S.; Olsson, L. Structuring problems in sustainability science: The multi-level DPSIR framework. Geoforum 2010, 41, 479-488. [CrossRef]

25. Hanne, S.; Lars, K.P.; Dale, R.; Henk, S.; Frank, W. Discursive biases of the environmental research framework DPSIR. Land Use Policy 2008, 25, 116-125.

26. Zhang, Z.G. A method of indicator-index coupling chain for two-step measurement of the threshold value and green degree of ecological civilization. China Popul. Resour. Environ. 2017, 27, 212-224.

27. Jiang, D.; Li, T.; Li, Z. The evaluation about the implementation impact of the s\&t policy in Hebei province. China Soft Sci. 2009, S1, 88-92, 111.

28. Milliken, P.J.; Schreiber, R. Examining the nexus between grounded theory and symbolic interactionism. Int. J. Qual. Methods 2012, 11, 684-696. [CrossRef]

29. Glaser, B.G.; Strauss, A.L.; Strutzel, E. The discovery of grounded theory; Strategies for qualitative research. Nurs. Res. 1968, 17, 364. [CrossRef]

30. Wang, L.; Gao, P. Grounded theory and its application in management research. Foreign Econ. Manag. 2010, 32, 10-18.

31. Glaser, B. Basics of Grounded Theory Analysis; Sociology Press: Mill Valley, CA, USA, 1992.

32. Strauss, A.; Corbin, J. Basics of Qualitative Research: Grounded Theory Procedures and Techniques; Sage Publications: Newbury Park, CA, USA, 1990.

33. Chen, X. Grounded theory: Its train of thought and methods. Educ. Res. Exp. 1999, 4, 58-63.

34. Tian, L. Review on grounded theory and its application. Econ. Res. Guide 2012, 10, 224-226.

35. Liu, X.; Zhou, J.; Xue, Y.; Qian, S. Analysis of property management ecological behavior in China based on the grounded theory: The influencing factors and the behavior model. J. Clean. Prod. 2019, 235, 44-56. [CrossRef]

36. Glaser, B. Theoretical Sensitivity: Advances in the Methodology of Grounded Theory; Sociology Press: Mill Valley, CA, USA, 1978.

37. Creswell, J.W.; Poth, C.N. Qualitative Inquiry and Research Design: Choosing Among Five Traditions; Sage Publications: Thousand Oaks, CA, USA, 1998.

38. Sun, X. Grounded theory: Theory-development in in-depth interview research. J. Xi'an Jiaotong Univ. 2011, 31, 87-92.

39. Fendt, J.; Sachs, W. Grounded theory method in management research: Users' perspectives. Organ. Res. Methods. 2008, 11, 430-455. [CrossRef]

40. He, Y.; Shi, D. Study on Grounded Theory in Social Surveys. World Surv. Res. 2009, 5, 46-48.

41. Cao, Q.; Sarker, M.N.I.; Sun, J. Model of the influencing factors of the withdrawal from rural homesteads in China: Application of grounded theory method. Land Use Policy 2019, 85, 285-289. [CrossRef]

42. Fadeyi, M.O.; Jallow, A.K.; Anumba, C.; Dulaimi, M. Process Management Approach for Achieving Total Building Performance: Essential Requirements for Sustainable Construction. In Proceedings of the Architectural Engineering Conference, State College, PA, USA, 3-5 April 2013.

43. Yang, S.; Su, Y.; Wang, W.; Hua, K. Research on Developers' Green Procurement Behavior Based on the Theory of Planned Behavior. Sustainability 2019, 11, 2949. [CrossRef] 